\title{
In vitro survival and germination of Candida albicans in the presence of nitrogen compounds
}

\author{
Fernando Abaitua, Aitor Rementería, Rosario San Millan, \\ Ainhoa Eguzkiza, Jose Antonio Rodriguez, José Pontón \\ and María Jesús Sevilla
}

Departamento de Inmunología, Microbiología y Parasitología, Universidad del País Vasco, Apartado 644, 48080-Bilbao, Spain

\begin{abstract}
Author for correspondence: María Jesús Sevilla. Tel: +34 946012688. Fax: +34944648500. e-mail : ippsegam@lg.ehu.es
\end{abstract}

Keywords: Nitric oxide, sodium nitroprusside, candidacidal activity, dimorphism, Candida albicans

\section{INTRODUCTION}

Phagocytosis is probably the most important mechanism in protecting the non-compromised host against invasive candidiasis (Domer \& Carrow, 1989). Polymorphonuclear leukocytes and macrophages, the main phagocytic cells involved in the clearance of fungal pathogens (Levitz, 1992), have different candidacidal mechanisms and different abilities to kill Candida albicans.

Nitric oxide (NO) is generated by the NO synthase of activated macrophages, but its real contribution to the candidacidal activity of murine macrophages is not clear, although it is certainly involved (Blasi et al., 1995; Cenci et al., 1993; Rementería et al., 1995; VazquezTorres et al., 1994). Thus some authors have correlated candidacidal activity of murine macrophages with peroxynitrite resulting from the interaction between NO and the superoxide anion (Vazquez-Torres et al., 1996). Others argue that the two compounds do not occur simultaneously in murine macrophages (Assreuy et al., 1994). In fact, there are few data about the susceptibility of C. albicans to nitric oxide in vitro in the absence of macrophages (Fierro et al., 1996).

Abbreviations: SNAP, S-nitroso-N-acetylpenicillamine; SNP, sodium nitroprusside.
C. albicans is a dimorphic fungus which can cause severe infections in immunocompromised patients. The ability of the fungus to modify its morphology from blastoconidia to hyphae is considered a virulence factor. Blastoconidia and hyphae show different susceptibility to phagocytic cells (Baccarini et al., 1985; Blasi et al., 1995; Cutler \& Poor, 1981), so they are probably diversely affected by macrophage products.

Our purpose was to study the in vitro susceptibility of blastoconidia and hyphae of C. albicans to NO in nutrient and $\mathrm{pH}$ conditions similar to those found in the phagolysosome or outside the macrophage, and the effect of this compound on the germination process of the fungus.

\section{METHODS}

Assay media. Two different assay media were used: (1) a minimal medium (MM) containing $1 \mathrm{~g}$ glucose $\mathrm{l}^{-1}$ and $0.5 \mathrm{~g}$ biotin $\mathrm{l}^{-1}$ in $0.08 \mathrm{M}$ citrate/phosphate buffer; and (2) a complex medium, consisting of Dulbecco modified Eagle's medium in $0.08 \mathrm{M}$ citrate/phosphate buffer (DMEB). The $\mathrm{pH}$ of both media was adjusted to $4 \cdot 5$ or $7 \cdot 0$. Sodium nitroprusside (SNP), sodium nitrite or $S$-nitroso- $N$-acetylpenicillamine (SNAP), at the concentrations indicated in the results, were added when necessary.

Micro-organism, maintenance and inoculum. The following 
C. albicans strains were used: CA-2 (agerminative mutant, kindly provided by A. Cassone, Istituto Superiore di Sanità, Rome, Italy); CA-6 (isolated from a clinical specimen, kindly provided by E. Blasi, University of Modena, Italy); 3153 (National Collection of Pathogenic Fungi, Public Health Laboratory, Bristol, UK); C2T, C9S and 2282 (Universidad del País Vasco culture collection). The strains were maintained on GYE agar $\left(20 \mathrm{~g}\right.$ glucose $\mathrm{l}^{-1} ; 10 \mathrm{~g}$ yeast extract $\mathrm{l}^{-1}$; $20 \mathrm{~g} \mathrm{agar}^{-1}$ ) by weekly transfer. Blastoconidia were obtained from $24 \mathrm{~h}$ cultures on GYE agar, washed with saline and adjusted to the desired concentration by direct counting under the microscope. Hyphae were obtained from CA-6 blastoconidia $\left(4 \times 10^{5}\right.$ cells $\left.\mathrm{ml}^{-1}\right)$ germinated in 96-well microassay plates in DMEB $\mathrm{pH} 7.0(100 \mu \mathrm{l}$ per well $)$ at $37^{\circ} \mathrm{C}$ for $3 \mathrm{~h}$.

Anti-C. albicans blastoconidia (anti-Y) assay. C. albicans CA$2\left(5 \times 10^{5}\right.$ blastoconidia $\left.\mathrm{ml}^{-1}\right)$ were incubated in the assay media at $37^{\circ} \mathrm{C}$ for $90 \mathrm{~min}$; the viability of the blastoconidia was determined as colony forming units (c.f.u.) on Sabouraud agar plates after incubation at $37^{\circ} \mathrm{C}$ for $24 \mathrm{~h}$. The anti-Y activity was calculated as follows:

Anti-Y activity $=[1-$ (c.f.u. in assay $/$ c.f.u. in control $)] \times 100$

Anti-C. albicans hyphae (anti-H) assay. CA-6 hyphae were incubated in the assay media at $37^{\circ} \mathrm{C}$ for $90 \mathrm{~min}$; the viability of the hyphae was determined by the MTT [3-(4,5-dimethylthiazol-2-yl)-2,5-diphenyltetrazolium bromide] reduction method (Mosmann, 1983). Briefly, $100 \mu \mathrm{l}$ DMEB and $10 \mu \mathrm{l}$ MTT ( $5 \mathrm{mg} \mathrm{m}^{-1}$ in $10 \mathrm{mM}$ sodium phosphate buffer $\mathrm{pH} 7 \cdot 2$ with $0.85 \%$ sodium chloride) were added to each well and the plate was incubated at $37^{\circ} \mathrm{C}$ for $3 \mathrm{~h}$. The medium was then removed and $100 \mu \mathrm{l}$ DMSO was added to each well. The absorbance at $540 \mathrm{~nm}$ was determined. The anti-H activity was calculated as follows:

Anti-H activity $=\left[1-\left(A_{540}\right.\right.$ in assay $/ A_{540}$ in control $\left.)\right] \times 100$

Morphology studies. C. albicans blastoconidia $\left(1 \times 10^{7}\right.$ cells $\mathrm{ml}^{-1}$ ) were incubated in $200 \mu \mathrm{l}$ assay media in siliconized tubes at $37^{\circ} \mathrm{C}$ for $3 \mathrm{~h}$. Fixing solution $(10 \%$ sodium lauryl sulfate, $10 \%$ formaldehyde; $20 \mu \mathrm{l}$ ) was added, and the samples kept at room temperature until necessary. Morphology was examined under an image analysis system (VIDS-IV) connected to a phase-contrast microscope. The percentage germination and the relative rate of hyphal elongation were determined as follows :

$\%$ Germination $=$

(number of hyphae/total number of cells) $\times 100$

Relative rate of hyphal elongation $=$

(length of hyphae in assay/length of hyphae in control) $\times 100$

The length of at least 100 hyphae across the slide was determined.

NO determination. NO was indirectly determined as nitrite using the Griess reagent (Granger et al., 1990). Briefly, $0.4 \mathrm{ml}$ $1 \%(\mathrm{w} / \mathrm{v})$ sulfanilamide in $2.5 \%(\mathrm{v} / \mathrm{v})$ phosphoric acid and $0.4 \mathrm{ml} 0.5 \%$ (w/v) N-(1-naphthyl)ethylenediamine dihydrochloride in $2.5 \%(\mathrm{v} / \mathrm{v})$ phosphoric acid were added to $0.2 \mathrm{ml}$ of sample. After $10 \mathrm{~min}$ at room temperature the absorbance at $540 \mathrm{~nm}$ was determined. Sodium nitrite $(0-25 \mu \mathrm{M})$ was used for the calibration curve.

Statistics. The Student's $t$-test was applied to the data. The differences were considered significant when $P<0.05$.

\section{RESULTS}

\section{NO generation by SNP}

First, the production of NO by SNP in the assay media without cells was quantified (Tables 1 and 2). In both media the NO generated was time-dependent and there was a good linear correlation between SNP concentration and NO produced. There were no significant differences in $\mathrm{NO}$ production between the two $\mathrm{pHs}$ or between the two media used. In all cases, the $\mathrm{pH}$ of the medium remained constant during the assay (data not shown).

\section{Effect of SNP and nitrite on C. albicans viability}

Once the linear relationship between SNP concentration and NO had been determined, we studied the effect of SNP and nitrite on the viability of blastoconidia and hyphae of $C$. albicans. SNP had a clear candidacidal effect against blastoconidia of $C$. albicans in $\mathrm{MM}$ at both pHs (Fig. 1). The effect was much greater at the acidic $\mathrm{pH}$. When the assay was run in DMEB in acidic conditions, an anti-Y effect of SNP was also observed, while at neutral $\mathrm{pH}$ only $4 \mathrm{mM}$ SNP showed a significant, though small, effect.

Table 1. NO (as nitrite, $-\mu \mathrm{M}$ ) generated by different concentrations of SNP in MM

Data represent the mean $\pm S D$ of at least three independent determinations.

\begin{tabular}{|c|c|c|c|c|}
\hline \multirow{2}{*}{$\begin{array}{l}\text { SNP } \\
(\mathrm{mM})\end{array}$} & \multicolumn{2}{|c|}{$\mathrm{pH} 4 \cdot 5$} & \multicolumn{2}{|c|}{$\mathrm{pH} 7 \cdot 0$} \\
\hline & $1.5 \mathrm{~h}$ & $3 \mathbf{h}$ & $1.5 \mathrm{~h}$ & $3 \mathrm{~h}$ \\
\hline 0 & $0 \cdot 0 \pm 0 \cdot 0$ & $0 \cdot 0 \pm 0 \cdot 0$ & $0 \cdot 0 \pm 0 \cdot 0$ & $0 \cdot 0 \pm 0 \cdot 0$ \\
\hline 1 & $4.77 \pm 1.32$ & $7 \cdot 02 \pm 0 \cdot 62$ & $4.94 \pm 0.63$ & $6 \cdot 41 \pm 0 \cdot 22$ \\
\hline 2 & $7 \cdot 24 \pm 2 \cdot 16$ & $13 \cdot 61 \pm 2 \cdot 32$ & $7 \cdot 16 \pm 1 \cdot 06$ & $12.06 \pm 1.76$ \\
\hline 4 & $14 \cdot 53 \pm 1 \cdot 12$ & $27 \cdot 5 \pm 2 \cdot 41$ & $15 \cdot 32 \pm 3 \cdot 39$ & $24 \cdot 92 \pm 1 \cdot 66$ \\
\hline 8 & $38 \cdot 80 \pm 6 \cdot 74$ & $65 \cdot 58 \pm 10 \cdot 60$ & $41.04 \pm 14.98$ & $53 \cdot 85 \pm 2 \cdot 74$ \\
\hline
\end{tabular}

Table 2. NO (as nitrite, $\mu \mathrm{M}$ ) generated by different concentrations of SNP in DMEB

Data represent the mean \pm SD of at least three independent determinations.

\begin{tabular}{|c|c|c|c|c|}
\hline \multirow{2}{*}{$\begin{array}{l}\text { SNP } \\
(\mathbf{m M})\end{array}$} & \multicolumn{2}{|c|}{$\mathrm{pH} 4 \cdot 5$} & \multicolumn{2}{|c|}{$\mathrm{pH} 7 \cdot 0$} \\
\hline & $1.5 \mathrm{~h}$ & $3 \mathrm{~h}$ & $1.5 \mathrm{~h}$ & $3 \mathrm{~h}$ \\
\hline 0 & $0 \cdot 0 \pm 0 \cdot 0$ & $0.0 \pm 0.0$ & $0 \cdot 0 \pm 0 \cdot 0$ & $0 \cdot 0 \pm 0 \cdot 0$ \\
\hline 1 & $5.65 \pm 0.25$ & $9 \cdot 50 \pm 1 \cdot 95$ & $5 \cdot 32 \pm 0 \cdot 25$ & $7 \cdot 79 \pm 1 \cdot 62$ \\
\hline 2 & $10 \cdot 19 \pm 2 \cdot 40$ & $21 \cdot 25 \pm 3 \cdot 26$ & $10 \cdot 66 \pm 1.29$ & $16 \cdot 83 \pm 2 \cdot 11$ \\
\hline 4 & $21 \cdot 29 \pm 6 \cdot 89$ & $32 \cdot 83 \pm 13 \cdot 72$ & $21 \cdot 48 \pm 5 \cdot 79$ & $27 \cdot 90 \pm 5.57$ \\
\hline 8 & $55 \cdot 35 \pm 8 \cdot 18$ & $59 \cdot 30 \pm 2 \cdot 22$ & $50 \cdot 19 \pm 11 \cdot 10$ & $57 \cdot 77 \pm 4 \cdot 17$ \\
\hline
\end{tabular}




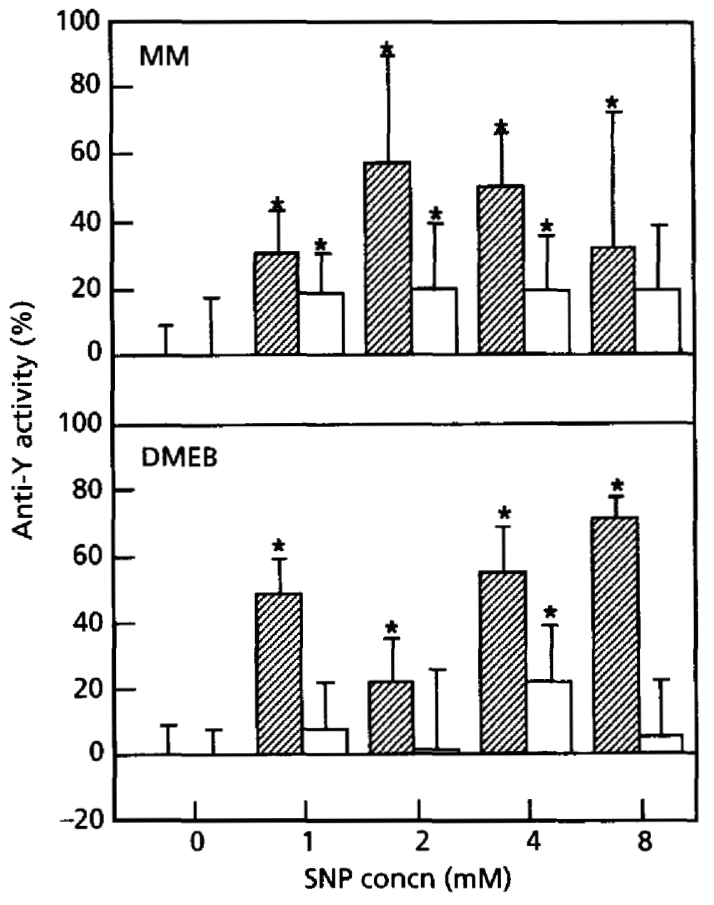

Fig. 1. Effect of SNP on the viability of $C$. albicans CA-2 yeast cells incubated at pH $4.5(\mathrm{Q})$ or $7.0(\square)$ in MM or DMEB. Data represent the mean $\pm S D$ of at least three independent determinations. Statistically significant differences with respect to controls are marked with an asterisk.

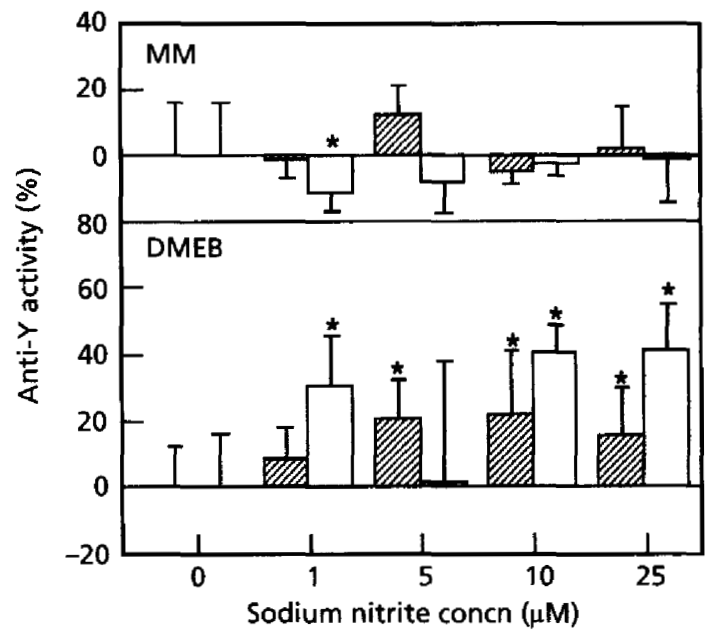

Fig. 2. Effect of sodium nitrite on the viability of $C$. albicans CA-2 yeast cells incubated at $\mathrm{pH} 4.5(\mathrm{Q})$ or $7.0(\square)$ in MM or DMEB. Data represent the mean \pm SD of at least three independent determinations. Statistically significant differences with respect to controls are marked with an asterisk.

Conversely, nitrite had no anti-Y effect when the incubation medium was MM (Fig. 2) but it was candidacidal against blastoconidia when the incubation medium was DMEB, and in that case, the effect was

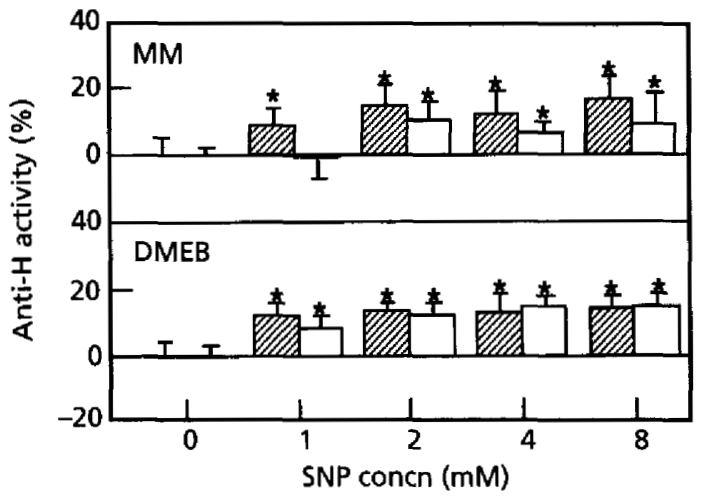

Fig. 3. Effect of SNP on the viability of C. albicans CA-6 hyphae at $\mathrm{pH} 4.5(\mathrm{Z})$ or $7.0(\square)$ in MM or DMEB. Data represent the mean $\pm S D$ of at least three independent determinations. Statistically significant differences with respect to controls are marked with an asterisk.

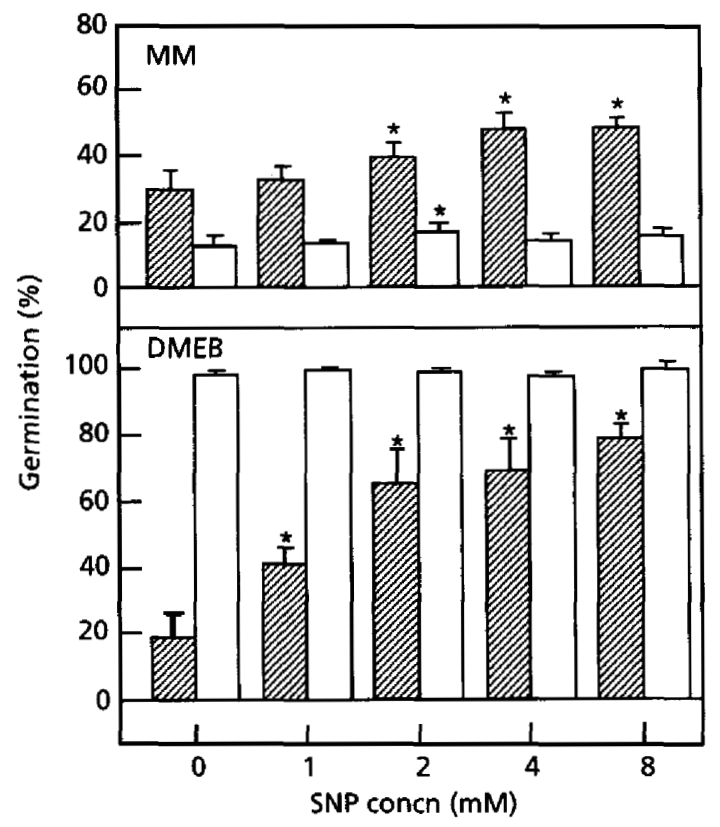

Fig. 4. Effect of SNP on the percentage germination of $C$. albicans CA-6 at pH 4.5 ( $\square$ ) or 7.0 (口) in MM or DMEB. Data represent the mean $\pm S D$ of at least three independent determinations. Statistically significant differences with respect to controls are marked with an asterisk.

greater at neutral $\mathrm{pH}$. We cannot explain the lack of significance of the activity of $5 \mathrm{mM}$ sodium nitrite in DMEB $\mathrm{pH} 7 \cdot 0$, apart from the wide dispersion of the data.

The effect of SNP on C. albicans hyphae was much lower than the effect on blastoconidia, both in MM and in $\mathrm{DMEB}$, and the differences between $\mathrm{pH}$ values were not significant (Fig. 3). Nitrite, on the other hand, had practically no anti-H effect in the different conditions 


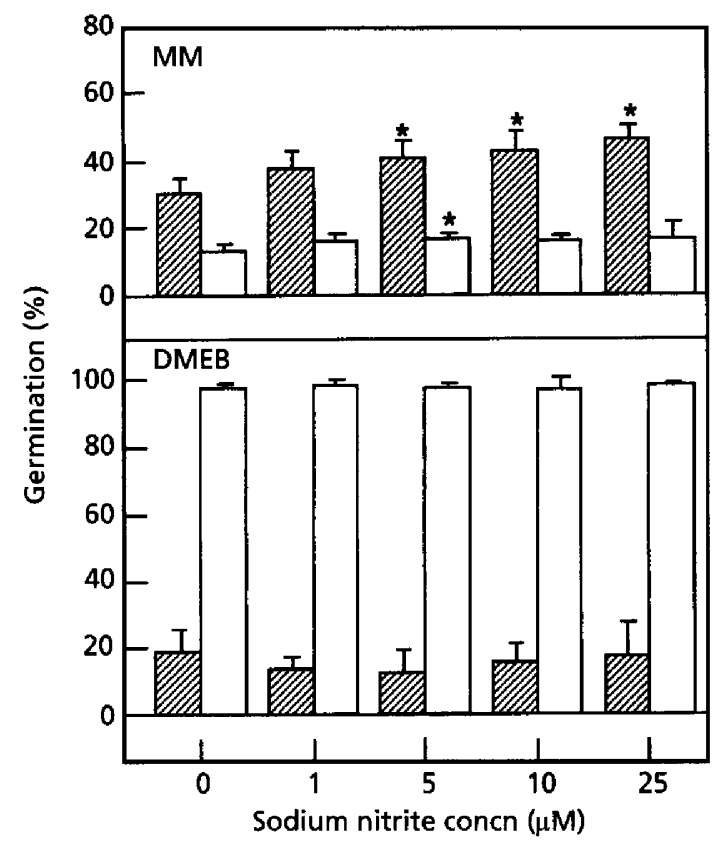

Fig. 5. Effect of sodium nitrite on the percentage germination of C. albicans CA-6 at pH 4.5 (घ) or $7.0(\square)$ in MM or DMEB. Data represent the mean $\pm S D$ of at least three independent determinations. Statistically significant differences with respect to controls are marked with an asterisk.

studied, except for $10 \mu \mathrm{M}$ nitrite in $\mathrm{MM} \mathrm{pH} \mathrm{7.0,} \mathrm{where}$ a small anti-H effect (less than $10 \%$ ) was observed (data not shown).

\section{Effects of SNP and nitrite on C. albicans morphology}

The germination of C. albicans CA- 6 was low in MM and in DMEB in acidic conditions, but it was $100 \%$ in DMEB pH 7.0 (Fig. 4). In DMEB pH 4.5, but not in $\mathrm{MM}$, pseudohyphae were frequently observed, although they were not quantified nor included in the percentage of true germination. The addition of SNP enhanced the germination of CA- 6 in MM and DMEB at $\mathrm{pH} 4.5$ in a dose-dependent pattern, although $100 \%$ germination was not achieved (Fig. 4); the increase in the percentage germination, attributed to NO, was simultaneous with the decrease in the proportion of pseudohyphae. No effect was detected in MM pH 7.0, nor, obviously, in DMEB $\mathrm{pH} 7 \cdot 0$ where the starting point was already $100 \%$.

Nitrite added to MM had a minor effect on the germination of CA-6 (Fig. 5), but the differences in comparison to the control, though statistically significant, were very small. When this compound was added to DMEB, no effect on the morphology was observed at any of the pHs studied.

The effect of SNP on the germination of strain CA-6 was so conspicuous that we tested five more strains, in-
Table 3. Effect of SNP on the percentage germination of different $C$. albicans strains in DMEB pH 4.5

Data represent the mean \pm SD of at least three independent determinations.

\begin{tabular}{|lcc|}
\hline Strain no. & Control & SNP $(4 \mathrm{mM})^{*}$ \\
\hline C9s & $21 \cdot 5 \pm 2 \cdot 1$ & $85 \cdot 0 \pm 2 \cdot 8$ \\
3153 & $51 \cdot 0 \pm 11 \cdot 3$ & $74 \cdot 0 \pm 5 \cdot 7$ \\
C2T & $5 \cdot 0 \pm 4 \cdot 2$ & $52 \cdot 5 \pm 6 \cdot 4$ \\
2282 & $14 \cdot 0 \pm 0 \cdot 0$ & $31 \cdot 5 \pm 7 \cdot 8$ \\
CA-2 & $0 \cdot 0 \pm 0 \cdot 0$ & $6 \cdot 5 \pm 3 \cdot 5$ \\
\hline
\end{tabular}

*All values showed statistically significant differences with respect to controls.

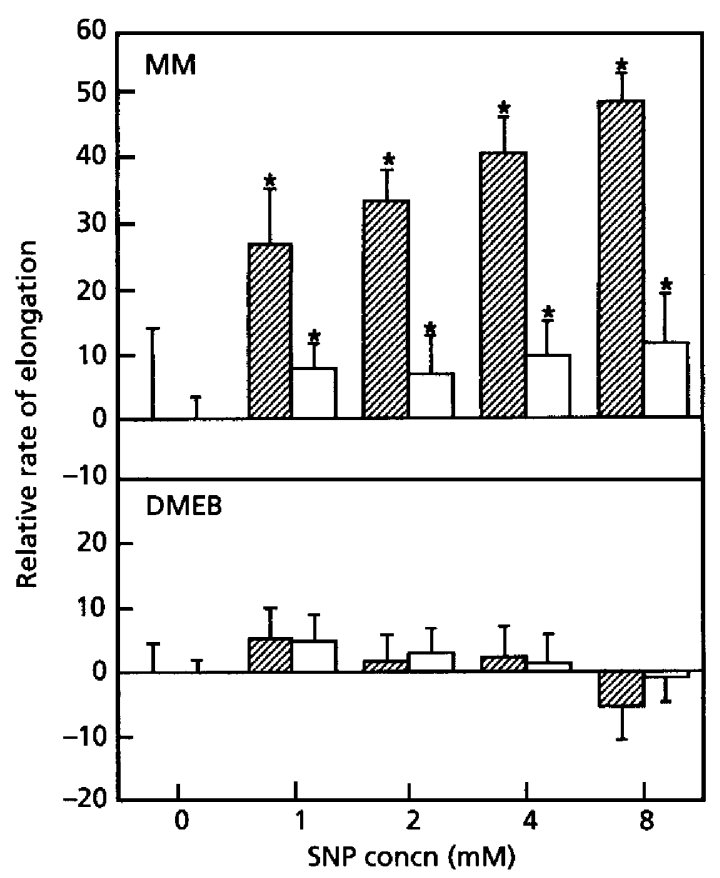

Fig. 6. Effect of SNP on the relative rate of elongation of $C$. albicans CA-6 germ tubes at $\mathrm{pH} 4.5(\square)$ or $7.0(\square)$ in MM or DMEB. Data represent the mean \pm SD of at least three independent determinations. Statistically significant differences with respect to controls are marked with an asterisk.

cluding the agerminative mutant CA-2, in DMEB $\mathrm{pH} 4.5$, to see if the effect was strain-specific. All strains tested showed a significant increase in the percentage germination when the NO donor was present (Table 3). In the case of CA-2, the increase in percentage germination was very low, but significant.

Finally we studied the effect of SNP and sodium nitrite on the elongation rate of C. albicans CA-6 hyphae. SNP significantly enhanced the elongation rate in $M M$, particularly in acidic conditions (Fig. 6). No significant 
effect of SNP was observed in DMEB. Nitrite had no significant effect on the elongation rate of C. albicans hyphae in any of the conditions used (data not shown).

\section{Effect of SNAP on the viability and morphology of C. albicans}

To prove more directly the involvement of $\mathrm{NO}$ in the observed effects of SNP on the viability and morphology of C. albicans, we studied the effect of another NO donor, SNAP. First, we observed that NO production by $5 \mathrm{mM}$ SNAP was quite variable, but it was at least as high as the amount produced by $8 \mathrm{mM}$ SNP in similar conditions, and frequently much greater (nitrite $=$ $230 \cdot 24 \pm 136 \cdot 07 \mu \mathrm{M})$. The $\mathrm{pH}$ of the media remained the same at the end of each experiment (data not shown).

The anti-Y activity of SNAP $5 \mathrm{mM}$ was qualitatively similar to the effect of SNP, with a greater candidacidal effect in acidic conditions (between 55\% in DMEB and $75 \%$ in $\mathrm{MM}$ ) than in the neutral ones (less than $20 \%$ in DMEB and $65 \%$ in $\mathrm{MM}$ ).

SNAP had no effect against C. albicans hyphae in any of the conditions tested (data not shown). On the contrary, it enhanced germination in DMEB $\mathrm{pH} 4.5$, increasing the percentage germination from $54 \%$ in the absence of SNAP to $91 \%$ when the compound was present.

\section{DISCUSSION}

NO production has been proposed as one of the major antimicrobial mechanisms of murine macrophages (MacMicking et al., 1997), which are active against different kinds of pathogens, such as viruses, bacteria, fungi, protozoa and helminths. The role of NO (or related compounds) in macrophage anti-Candida activities seems to be well-established (Rementería et al., 1995; Vazquez-Torres \& Balish, 1997). However, NO is a very labile molecule and there is no agreement on the anti-Candida effect of the different intermediates and derivatives.

Our purpose was to study the susceptibility of blastoconidia and hyphae of $C$. albicans to $\mathrm{NO}$ and the effect of this compound on the germination process. We designed a cell-free system with SNP or SNAP as NO donors, in different $\mathrm{pH}$ conditions and in different media to mimic, to some degree, the phagolysosomal ( $\mathrm{MM}$, $\mathrm{pH} 4.5$ ) and the extracellular (DMEB, $\mathrm{pH} 7 \cdot 0$ ) environments with respect to $\mathrm{pH}$ and nutrient availability. We studied the effect of sodium nitrite in similar conditions, because nitrite is always present in NO aqueous solutions (Granger et al., 1990) and is also reputed to be a microbicidal compound. In fact, we detected NO as nitrite since we could not distinguish clearly between the two compounds. A second NO donor was used to be sure that the effects attributed to NO were really due to this compound. In order to study the differential susceptibility of yeast and hyphal morphologies, we used two different $C$. albicans strains, CA-2, an agerminative mutant, and CA-6, a fully germinative strain. By using an agerminative mutant we were able to maintain the yeast phase in the assay conditions. We cannot exclude the possibility that differences between CA-6 and CA-2 may influence their interactions with the compounds tested in this study.

First, we demonstrated that NO production by SNP was time- and dose-dependent, whilst other assay conditions, such as $\mathrm{pH}$ or medium composition, did not significantly affect NO generation. We therefore used SNP concentration as an indicator of NO concentration in the assays.

C. albicans blastoconidia were susceptible to SNP and SNAP, especially in acidic conditions similar to those found in the phagolysosomal environment. C. albicans hyphae were more resistant to the nitrogen compounds in all the conditions tested. Little correlation was observed between the effect of the NO donors, SNP and SNAP, and the effect of nitrite on the viability of $C$. albicans. Consequently, we attribute the effect of SNP and SNAP mainly to $\mathrm{NO}$, rather than nitrite. The smaller effects of nitrite could be partially due to NO when the pH was acid (Stuehr \& Nathan, 1989), and may be due to the nitrite itself when the $\mathrm{pH}$ was neutral.

The effect of $\mathrm{pH}$ on the susceptibility of different microorganisms to NO has been previously reported by other authors (Buchmüller-Rouiller et al., 1994; Kono et al., 1994). A decrease in C. albicans viability in the presence of different NO donors was shown by Fierro et al. (1996), but no mention was made of a different susceptibility of yeast and hyphae. Blasi et al. (1995) reported that $C$. albicans hyphae are sensitive to the extracellular killing mechanism of murine macrophages mediated by nitrogen compounds but blastoconidia are not. This apparent contradiction with our results could be explained by the fact that macrophages produce not just NO, but a collection of toxic compounds whose synergistic effect could be totally different from the effect of each one separately. So the susceptibility of hyphae reported by Blasi et al. (1995) could be attributable to this synergistic effect. The resistance of C. albicans blastoconidia to extracellular NO could be explained in the same way or, perhaps, could be attributable to an insufficiently low $\mathrm{pH}$ in the assay. By contrast, evidence for the susceptibility of C. albicans blastoconidia to killing by NO-producing murine macrophages has already been published (Cenci et al., 1993; VazquezTorres et al., 1994, 1995) and it is generally accepted that C. albicans hyphae are more resistant to macrophage killing than blastoconidia (Cutler \& Poor, 1981).

The ability to produce hyphae by $C$. albicans blastoconidia is important as far as virulence is concerned (Richardson \& Smith, 1981; Saltarelli et al., 1975). The infectious unit is usually in the yeast form, and germination occurs in animal tissues after infection. Accordingly, we were interested in determining the effect of nitrogen intermediates on the germination process in addition to their effect on the viability of both morpho- 
logies. For that purpose, we used strain CA-6 as well as other C. albicans strains obtained from human patients. Although the germinative ability of these strains was diverse, in general they produced a maximum percentage of germ tubes in complex medium $\mathrm{pH} 7 \cdot 0$, whilst at $\mathrm{pH} 4.5$ the percentage germination was significantly reduced. This is in agreement with data reported by Kaur \& Mishra (1994).

Whilst nitrite did not affect the germination process, NO derived from SNP increased the percentage germination of all the C. albicans strains tested in acidic conditions. SNAP also enhanced the germination of CA-6 strain. Not only the percentage germination but even the elongation of hyphae of CA-6 was significantly enhanced by SNP in conditions equivalent to the intraphagolysosomal environment $(\mathrm{pH} 4 \cdot 5, \mathrm{MM})$. These observations suggest that $C$. albicans may be able to avoid the microbiocidal mechanisms of macrophages by changing its growth to the most resistant morphology, not to mention the fact that the intracellular growing hyphae destroy the macrophage (Evron, 1980). This would mean that NO-generating macrophages would help in the extension of the infection, as has been proposed by Brummer \& Stevens (1994). In fact, macrophages from mice infected with $C$. albicans produce significant amounts of NO (Rementería et al., 1995).

However, the in vivo data are not easy to reconcile with our in vitro studies. It has been reported that activated macrophages are able to retard the germination of yeast forms of C. albicans for several hours (Maiti et al., 1980). Additional experimental evidence is needed in order to extrapolate our data, obtained in vitro, to what happens in vivo.

In summary, we conclude that (1) C. albicans blastoconidia are more sensitive than hyphae to $\mathrm{NO}$; (2) C. albicans blastoconidia are susceptible to nitrite; (3) NO enhances germination; and (4) NO is more efficient in acidic conditions.

\section{ACKNOWLEDGEMENTS}

We thank Professor David Hallet for his revision of the English version of the manuscript.

This research was supported by grant UPV 093.327EB131/96 from the Universidad del Pais Vasco and grant EX97/4 from the Departamento de Educación, Universidades e Investigación del Gobierno Vasco.

\section{REFERENCES}

Assreuy, J., Cunha, F. Q., Epperlein, M., Noronha-Dutra, A., O'Donnell, C. A., Liew, F. Y. \& Moncada, S. (1994). Production of nitric oxide and superoxide by activated macrophages and killing of Leishmania major. Eur J Immunol 24, 672-676.

Baccarini, M., Vecchiarelli, A., Cassone, A. \& Bistoni, F. (1985). Killing of yeast, germ-tube and mycelial forms of Candida albicans by murine effectors as measured by radiolabel release microassay. J Gen Microbiol 131, 505-513.

Blasi, E., Pitzurra, L., Puliti, M., Chimienti, A. R., Mazzola, R.,
Barluzzi, R. \& Bistoni, F. (1995). Differential susceptibility of yeast and hyphal forms of Candida albicans to macrophage-derived nitrogen-containing compounds. Infect Immun 63, 1806-1809.

Brummer, E. \& Stevens, D. A. (1994). Anticryptococcal activity of macrophages: role of mouse strain, C5, contact, phagocytosis, and L-arginine. Cell Immunol 157, 1-10.

Buchmüller-Rouiller, Y., Corradin, S. B., Smith, J. \& Maüel, J. (1994). Effect of increasing intravesicular $\mathrm{pH}$ on nitrite production and leishmanicidal activity of activated macrophages. Biochem J 301, 243-247.

Cenci, E., Romani, L., Mencacci, A., Spaccapelo, R., Schiaffella, E., Puccetti, P. \& Bistoni, F. (1993). Interleukin-4 and interleukin-10 inhibit nitric oxide-dependent macrophage killing of Candida albicans. Eur J Immunol 23, 1034-1038.

Cutler, J. E. \& Poor, A. H. (1981). Effect of mouse phagocytes on Candida albicans in in vitro chambers. Infect Immun 31, 1110-1116.

Domer, J. E. \& Carrow, E. W. (1989). Candidiasis. In Immunology of the Fungal Diseases, pp. 57-92. Edited by R. A. Cox. Boca Raton, FL: CRC Press.

Evron, R. (1980). In vitro phagocytosis of Candida albicans by peritoneal mouse macrophages. Infect Immun 28, 963-971.

Fierro, I. M., Barja-Fidalgo, C., Cunha, F. Q. \& Ferreira, S. H. (1996). The involvement of nitric oxide in the anti-Candida albicans activity of rat neutrophils. Immunology 89, 295-300.

Granger, D. L., Hibbs, J. B. J., Perfect, J. R. \& Durack, D. T. (1990). Metabolic fate of L-arginine in relation to microbiostatic capability of murine macrophages. J Clin Investig 85, 264-273.

Kaur, S. \& Mishra, P. (1994). Differential increase in cytoplasmic $\mathrm{pH}$ at bud and germ tube formation in Candida albicans: studies of a nongerminative variant. Can J Microbiol 40, 720-723.

Kono, Y., Shibata, H., Adachi, K. \& Tanaka, K. (1994). Lactatedependent killing of Escherichia coli by nitrite plus hydrogen peroxide: a possible role of nitrogen dioxide. Arch Biochem Biophys 311, 153-159.

Levitz, S. M. (1992). Overview of host defenses in fungal infections. Clin Infect Dis 14 (suppl.1), S37-S42.

MacMicking, J., Xie, Q. \& Nathan, C. (1997). Nitric oxide and macrophage function. Annu Rev Immunol 15, 323-350.

Maiti, P. K., Kumar, R. \& Mohapatra, L. N. (1980). Candidacidal activity of mouse macrophages in vitro. Infect Immun 29, 477-482.

Mosmann, T. (1983). Rapid colorimetric assay for cellular growth and survival: application to proliferation and cytotoxicity assays. J Immunol Methods 65, 55-63.

Rementería, A., Garcia-Tobalina, R. \& Sevilla, M. J. (1995). Nitric oxide-dependent killing of Candida albicans by murine peritoneal cells during an experimental infection. FEMS Immunol Med Microbiol 11, 157-162.

Richardson, M. D. \& Smith, H. (1981). Production of germ tubes by virulent and attenuated strains of Candida albicans. J Infect Dis 144, 565-569.

Saltarelli, C. G., Gentile, K. A. \& Mancuso, S. C. (1975). Lethality of Candida strains as influenced by the host. Can J Microbiol 21, 648-654.

Stuehr, D. J. \& Nathan, C. F. (1989). Nitric oxide: a macrophage product responsible for cytostasis and respiratory inhibition in tumor target cells. J Exp Med 169, 1543-1555.

Vazquez-Torres, A. \& Balish, E. (1997). Macrophages in resistance to candidiasis. Microbiol Mol Biol Rev 61, 170-192.

Vazquez-Torres, A., Jones-Carson, J. \& Balish, E. (1994). 
Candidacidal activity of macrophages from immunocompetent and congenitally immunodeficient mice. J Infect Dis 170, 180-188.

Vazquez-Torres, A., Jones-Carson, J., Warner, T. \& Balish, E. (1995). Nitric oxide enhances resistance of SCID mice to mucosal candidiasis. J Infect Dis 172, 192-198.

Vazquez-Torres, A., Jones-Carson, J. \& Balish, E. (1996). Peroxy- nitrite contributes to the candidacidal activity of nitric oxideproducing macrophages. Infect Immun 64, 3127-3133.

Received 23 October 1998; revised 8 March 1999; accepted 22 March 1999. 